\title{
The Mandala of the Present Moment
}

\author{
William Van Gordon ${ }^{1}$ (D) $\cdot$ Edo Shonin ${ }^{2} \cdot$ Javier Garcia-Campayo $^{3}$
}

Published online: 16 August 2017

(C) Springer Science+Business Media, LLC 2017

"Mandala" is a Sanskrit word generally used to refer to a painting, diagram, or architectural structure with a particular symbolic meaning. Mandalas are often artistically beautiful and can be used to depict stages of the spiritual journey, the teachings or realm of a spiritual adept, or even life or the universe more generally. Perhaps the most well-known type of mandala are those comprising colored sand that can take many weeks to construct. In certain meditation traditions, the offering of a sand mandala concludes with the mandala being wiped with a brush to signify impermanence. Although mandalas often have elaborate designs, they can also be very simple. For example, there is an amusing story about the Indian Buddhist saint Naropa who was walking in the desert with his teacher, Tilopa. In his typical spontaneous manner, Tilopa decided to perform an initiation but Naropa had nothing on his person to offer his teacher. Consequently, Naropa proceeded to urinate in the sand in order to create a mandala that he could offer to his teacher. This was acceptable to Tilopa who then continued with the transmission.

Some people find mandalas to be useful aids to meditation and spiritual practice. Among other applications, they can help spiritual practitioners work mindfully (i.e., during the creation of the mandala), engage in purification and healing practices, request blessings from spiritual teachers, and remember the

William Van Gordon

w.vangordon@derby.ac.uk

1 Centre for Psychological Research, University of Derby, Kedleston Road, Derby, Derbyshire DE22 1GB, UK

2 Awake to Wisdom Centre for Meditation and Mindfulness Research, Ragusa, Italy

3 Miguel Servet University Hospital, University of Zaragoza, Zaragoza, Spain transitory nature of life and phenomena. This paper explores how the mandala principle can be used to deepen our relationship with the present moment.

\section{Center and Periphery}

Although mandalas are often constructed as visual objects (whether using materials or during visualization in meditation), the mandala principle extends much beyond creating a piece of art or visual structure. Indeed, one translation of the term mandala is that of "center and periphery." On first impression, "center and periphery" might appear dualistic and to thus contradict some of the core wisdom (Sanskrit prajña principles of meditation (e.g., that phenomena are interconnected to the extent that there is no clear divide between them). However, notwithstanding this limitation, for the reasons outlined below the notion of center and periphery can be an insightful means of understanding the mandala.

We experience the world at the level of the mind. This is a matter of basic science and is demonstrated by the process of saltatory conduction through the central nervous system. When our sensory receptors in, for example, the eyes or ears are stimulated (i.e., by light or sound), a chemical signal is transmitted through the central nervous system to the brain. However, what we perceive is the brain's reconstruction of reality based on how it interprets this signal. Consequently, the truth is that we never directly see, hear, smell, taste, or touch phenomena. We only experience our mind's reconstruction of them. We have the sensation of movement, but we never actually go anywhere. We have the sensation of seeing, but we never truly see something. The process of experiencing life at the level of the mind corresponds to the "center" aspect of the mandala. We are all at the center of our worlds. Nobody else shares our experiences. Other individuals may share 
similar experiences, but these experiences are not the same. They are not the same because each living being interprets and relates to the world differently.

Although we are at the center of our world, we are not the only living being or phenomenon that lives in the world. We interact and co-exist with all other phenomena in the universe. If a single piece of dust floating in distant space did not exist, then the entire universe would not exist. The existence of one thing implies the existence of all things. A person's mind exists because all minds exist, and in their construction of reality, they knowingly or unknowingly interact with every other mind in the universe. This is the "periphery" aspect of the mandala.

Thus, rather than being dualistic, at a more profound level the term "center and periphery" implies the whole of reality. Since reality can only unfold in the present moment, then a mandala can only exist in the present moment. Depending upon our view of reality, we can think of the present moment comprising many or just one mandala. We could think of there being a different mandala corresponding to the life of each living being, but we could also deem that an individual experiences many different mandalas during the course of a single day. For example, we create, experience, and then conclude a mandala when we eat breakfast. We could think of this as a short-term mandala. Other examples of short-term mandalas might be a thought or a single in-breath or out-breath. But we also experience a mandala when studying a new discipline, with our career, and with each individual with whom we have a relationship. Perhaps we could think of these as slightly longer-term mandalas.

Based on the above conceptualization, we can say that there exist mandalas within mandalas. In fact, there are actually an infinite number of mandalas, and the extent to which a mandala can encompass other mandalas is unlimited. For example, a city might be considered a mandala that exists as part of the larger mandala of the country in which it resides. But a country forms part of the mandala of the world, that in turn, forms part of the mandala of the universe. And the universe forms part of the mandala of the multiverse. According to string theory proposed by the field of quantum physics, the multiverse comprises multiple dimensions and therefore exists as part of a mandala that is much larger or even of infinite magnitude.

We like to refer to this larger-scale mandala as the "mandala of the present moment." The mandala of the present moment encompasses everything that exists and comprises an infinite number of smaller mandalas. However, the slightest movement or change in any one of these smaller mandalas influences all other mandalas. The energy and intention carried by a single breath or thought reverberates throughout time and space. When we start to understand this, it is a huge responsibility. It is a responsibility because we appreciate that although the mandala representing our individual lives might seem small or insignificant, with each thought, word, and action, we touch and influence the entire present moment as well as all future moments.

\section{Crafting the Mandala}

Much like crafting a mandala using sand, we each have the capacity to craft the mandala of the present moment. Crafting the mandala of the present moment might sound like it requires a lot of planning and mental energy. However, applying too much thought or mental energy does not embody the essence of mindful living. To be good at crafting the present moment, all we have to do is remain aware of it. Remember that we are at the center of our worlds and that this center is connected to the periphery. Therefore, if we practice presentmoment awareness and infuse our thoughts, words, and actions with gentleness and compassion, this positive intention touches everything residing at the periphery of our mandala.

Thinking in terms of a center and periphery is a conceptually useful means of relating to the mandala principle, particularly if we understand that the center and periphery encompass everything. Nevertheless, it is perhaps useful to reiterate that conceptualizations such as center and periphery are relative and limited notions. As previously discussed, we live out reality at the level of the mind and our perception of phenomena might not be as reliable as we think. Therefore, we should ask ourselves whether, in our mind-made reality, there truly exists a here and there, a near and far, a center and periphery, or a before and after. When we dream, do we really move anywhere, do we perform actions, and does the periphery occupy a different location than the center? What is the difference between dream reality and what we call waking reality? Are these realities not both the product of the mind? These are important questions to ask ourselves.

When we start to intuitively realize that we are living out reality at the level of the mind, we can move beyond concepts such as "center and periphery" and "space and time." Then, much like the rising sun that spreads warmth across the earth, we can establish ourselves in meditative equanimity and touch the minds of all living beings with joyful and compassionate energy. We can do this because in the realm of the mind, there exist no physical boundaries. In fact, if a spiritual practitioner's intention is pure enough, their joyful and compassionate energy can touch the heart and mind of a person sitting in the same room just as easily as it can touch somebody on the other side of the world. Of course, how other minds interpret this spiritual energy, and what they choose to do with it, is a matter for them.

The beautiful thing is that when we extend the roots of our being deep into the mandala of the present moment, the present moment starts to work with us. Tuning into the present moment allows us to see that there is a solution to every 
problem. The present moment does not want us to suffer. It wants to help us and it wants us to be well and happy. But to access the wisdom of the present moment, we need to relax into it and accept it as our closest friend. A few years ago, we conducted a randomized controlled trial involving managers working in office-based roles. The managers received training in an intervention that we developed called meditation awareness training. We embedded a qualitative arm within the study and analyzed manager's responses to a series of questions. The analysis yielded an outcome that we referred to as phenomena feedback effect. It appeared that when they were meditatively aware and able to let go of concepts and of wanting to be noticed or promoted, the managers were, at times, able to enter into a dialog with the present moment. They reported that the present moment started to point out the way for them. When I (William) observed this outcome, it brought a tear to my eye. It was a tear of joy because some of those participants had experienced something very beautiful. They had, for a short time, entered into a loving relationship with the mandala of the present moment and been touched by its wisdom. I hope they managed to maintain and develop this relationship.

\section{Wiping Clean the Mandala}

As discussed previously, wiping the mandala clean is used as a means of remembering impermanence. This is basically what happens when we die. The mandala of life is wiped clean so that we can begin the construction of a new mandala. Although the mandala representing our life will be wiped clean whether we like it or not, the good news is that as individuals walking the path of meditation, we can familiarize ourselves with the wiping process. Developing this familiarity will help us to remain calm, centered, and without fear when the time comes for our mandala to be wiped clean.

The way to foster this familiarity is to become skilled in the art of letting go. At the moment an experience arises, it ceases to exist. The present moment is like a flowing river that does not remain static even for an instant. It simply does not make sense to try to hold onto something that is continuously changing. This is the essence of mindful living. Mindfulness is about being aware of experience as it unfolds at the level of the mind, and then letting go of that experience so that we can embrace the next experience with a mind that is open and untainted by concepts or expectations. A good mindfulness practitioner is an individual that wipes their mandala clean every day, or ideally, many times each day. By choosing to practice letting go and wiping clean our mandala on a daily basis, when the time comes for us to leave this world, the process will not be so painful or confusing. In fact, there is no reason why we cannot thoroughly enjoy our transition from this world to the next. Becoming adept at the practice of letting go means that, paradoxically, we can find continuity at the time of death. In other words, it is possible to familiarize ourselves with the process of impermanence to such an extent that a sense of permanence begins to emerge. The realization that impermanence is permanent serves as a point of reference or refuge for the mind during the natural process of our life mandala being wiped clean by the brush of impermanence.

\section{The Mandala of Letting Go}

As previously discussed, letting go is paramount to the crafting of our life mandala (and therefore the mandala of the present moment), and letting go is also important when the time comes for our life mandala to be wiped clean. It is easy to advise people to "let go" but we would like to conclude this paper by highlighting that letting go is not easy. It is difficult to let go of our experiences because we have become so accustomed to holding onto them. Furthermore, to greater or lesser extents, the teachings of all authentic spiritual traditions encourage us to foster love and compassion for all forms of life. Being loving and compassionate requires us to reach out to people with all of our heart and being. This advice seems to run contrary to the practice of letting go.

The way to overcome the apparent contradiction between letting go and helping others is to cultivate a view that fuses compassion and wisdom. Compassion drives us to feel other being's suffering and take appropriate action to help them overcome it. But wisdom helps us to remember that we are working in the realm of the mind where phenomena are empty of intrinsic existence. This is basically what is implied by mandalas that depict a spiritual being in sexual union with a consort. The consort, who is usually in female form, signifies emptiness whereas the male energy represents action and compassion.

Letting go can be difficult but the more we practice it, the easier it becomes. In fact, the choice we are presented with is simple. We can suffer and delude ourselves due to holding onto something that no longer exists. Or we can be courageous, take a deep breath, and let go of mindmade reality at the same moment we experience it. When we are courageous in this manner, we start to taste freedom because we understand that in fact, there is nothing to let go of. We reach a point where we have let go of having to let go. How splendid!

\section{Compliance with Ethical Standards}

Conflict of Interest The authors declare that they have no conflicts of interest. 